\title{
Visual Deprivation Reactivates Rapid Ocular Dominance Plasticity in Adult Visual Cortex
}

\author{
Hai-Yan He, ${ }^{2}$ William Hodos, ${ }^{1,3}$ and Elizabeth M. Quinlan ${ }^{1,2}$ \\ ${ }^{1}$ Neuroscience and Cognitive Sciences Program and Departments of ${ }^{2}$ Biology and ${ }^{3}$ Psychology, University of Maryland, College Park, Maryland 20742
}

\begin{abstract}
Brief monocular deprivation ( $\leq 3 \mathrm{~d}$ ) induces a rapid shift in the ocular dominance of binocular neurons in the juvenile rodent visual cortex but is ineffective in adults. Here, we report that persistent, rapid, juvenile-like ocular dominance plasticity can be reactivated in adult rodent visual cortex when monocular deprivation is preceded by visual deprivation. Ocular dominance shifts in visually deprived adults are caused by a rapid depression of the response to stimulation of the deprived eye, previously only reported in juveniles, and a simultaneous potentiation of the response to stimulation of the nondeprived eye. The enhanced ocular dominance plasticity induced by visual deprivation persists for days, even if binocular vision precedes monocular deprivation. Visual deprivation also induces a significant decrease in the level of $\mathrm{GABA}_{\mathrm{A}}$ receptors relative to AMPA receptors and a return to the juvenile form of NMDA receptors in the visual cortex, two molecular changes that we propose enable the persistent reactivation of rapid ocular dominance plasticity.
\end{abstract}

Key words: visual deprivation; ocular dominance; $\mathrm{AMPA}$ receptor; $\mathrm{NMDA}$ receptor; $\mathrm{GABA}_{\mathrm{A}}$ receptor; synaptic plasticity

\section{Introduction}

The ocular dominance of binocular neurons in the visual cortex is actively maintained by competition between synapses serving the two eyes. Depriving one eye of vision induces a shift in ocular dominance toward the nondeprived eye (Hubel and Wiesel, 1970). In juvenile rodents, brief ( $\leq 3 \mathrm{~d}$ ) monocular deprivation (MD) induces a rapid depression of the response to stimulation of the deprived eye, followed by a slower potentiation of the response to stimulation of the nondeprived eye (Frenkel and Bear, 2004). These effects of monocular deprivation are blocked by antagonists of the NMDA subtype of glutamate receptor (Bear et al., 1990) and occlude long-term depression induced by lowfrequency stimulation (Heynen et al., 2003). In adults, brief monocular deprivation does not induce an ocular dominance shift (Gordon and Stryker, 1996; Sawtell et al., 2003). However, prolonged ( $\geq 5 \mathrm{~d}$ ) monocular deprivation effectively shifts ocular dominance attributable entirely to a potentiation of the response to stimulation of the nondeprived eye. The effects of monocular deprivation in adults share many features with the long-term potentiation (LTP) of synaptic strength induced by high-frequency stimulation, including dependence on NMDA receptor (NMDAR) activation (Heynen and Bear, 2001; Sawtell et al., 2003).

A primary determinant of the level of synaptic plasticity available within the visual system is the balance between cortical inhibition and excitation (I/E) (Fagiolini and Hensch, 2000; Rozas et al., 2001). Over the course of postnatal development, there is an

Received Dec. 27, 2005; revised Jan. 30, 2006; accepted Feb. 2, 2006.

This work was supported by National Institutes of Health Grant EY13818 and Whitehall Foundation Grant 05-72. We thank Feng Rong for expert technical assistance and Dr. Hey-Kyoung Lee for critical comments on this manuscript.

Correspondence should be addressed to Elizabeth M. Quinlan, 3245 Biology/Psychology Building \#144, University of Maryland, College Park, MD 20742. E-mail: equinlan@umd.edu.

D01:10.1523/JNEUROSCI.5554-05.2006

Copyright $\odot 2006$ Society for Neuroscience $\quad$ 0270-6474/06/262951-05\$15.00/0 increase in the strength of GABAergic inhibition relative to glutamatergic excitation and a concomitant decrease in the level of ocular dominance plasticity (Huang et al., 1999; Rozas et al., 2001; Desai et al., 2002). In addition, there is developmental regulation of NMDAR composition and function (Carmignoto and Vicini 1992; Quinlan et al., 1999), resulting in changes in the properties of NMDAR-dependent synaptic plasticity. Depriving an animal of vision from birth maintains the visual system in an immature state, characterized by low stimulus selectivity and large receptive fields (Fagiolini et al., 1994). Dark rearing also attenuates the development decline in ocular dominance plasticity (Cynader, 1983), the developmental increase in inhibition relative to excitation (Desai et al., 2002; Morales et al., 2002), and the maturation of NMDARs (Carmignoto and Vicini, 1992; Quinlan et al., 1999). The effects of visual deprivation in a normally reared adult are less well understood. Here, we show that visual deprivation in adulthood reactivates a persistent, juvenilelike response to brief $\mathrm{MD}$, evident as a rapid depression of the response to stimulation of the deprived eye and a potentiation of the response to stimulation of the nondeprived eye. In addition, visual deprivation induces a significant decrease in the level of $\mathrm{GABA}_{\mathrm{A}}$ receptors $\left(\mathrm{GABA}_{\mathrm{A}} \mathrm{Rs}\right)$ relative to AMPA receptors (AMPARs) and a return to the juvenile form of NMDARs, two changes that we propose enable the persistent reactivation of rapid ocular dominance plasticity in adults.

\section{Materials and Methods}

Adult [postnatal day 70 (P70) to P100] male and female pigmented LongEvans rats were raised on a $12 \mathrm{~h}$ light/dark cycle, with food and water available ad libitum. Subjects were moved into a light-tight dark room at indicated ages for visual deprivation. All procedures conform to the guidelines of the U.S. Department of Health and Human Services and the University of Maryland Institutional Animal Care and Use Committee.

Monocular deprivation. Animals were anesthetized with ketamine/xylazine $(50 \mathrm{mg} / 10 \mathrm{mg} / \mathrm{kg}$, i.p.). The margins of the upper and lower lids of 
one eye were trimmed and sutured together. The animals were returned to their home cages for $3 \mathrm{~d}$ and disqualified in the event of suture opening or infection.

Visually evoked potential recordings. Animals were anesthetized with urethane (1.6 g/kg, i.p.). Body temperature and dominant EEG frequency (in response to blank screen) were used to monitor anesthetic depth. A bilateral craniotomy was performed over binocular visual cortex (centered at $7.0 \mathrm{~mm}$ posterior to bregma and $4 \mathrm{~mm}$ lateral to midline), keeping dura intact. Visually evoked potentials (VEPs) were recorded from the binocular visual cortex with tungsten microelectrodes (0.5 M $\Omega$; MPI, Gaithersburg, MD) relative to a reference electrode in the neck muscle. Assessment of the VEP in response to stimulation of ipsilateral eye confirmed electrode placement in binocular visual cortex.

The visual stimulus was a $1 \mathrm{~Hz}$ full-screen vertical square wave grating $\left(0.04\right.$ cycles $\left.^{\circ}\right)$ with $96.28 \%$ maximal contrast. The amplitude of the primary positive component was used to assess the cortical response to visual stimulation. VEPs were amplified $(1000 \times)$, filtered $(0.5$ and 300 $\mathrm{Hz}$ ), and averaged (100 repetitions) in synchrony with the stimulus using an IBM-compatible computer with Enfant software (Enfant 4010; NeuroScientific, Farmingdale, NY). The data were then digitally filtered with a $60 \mathrm{~Hz}$ low-pass filter before analysis.

Quantitative immunoblots. Binocular visual and frontal cortices were dissected bilaterally after anesthetization with sodium pentobarbital (75 $\mathrm{mg} / \mathrm{kg}$, i.p.). Synaptoneurosomes and quantitative immunoblotting were performed as described previously (Quinlan et al., 1999; He et al., 2004). Primary antibodies included anti-GluR2 (clone 6C4; Zymed, San Francisco, CA), anti-GABA ${ }_{\mathrm{A}} \beta 2 / 3$ (clone 62-3G1; Upstate Biotechnology, Lake Placid, NY), anti-actin (clone JLA20; Oncogene Sciences, Uniondale, NY), anti-NR2A (rabbit polyclonal; Upstate Biotechnology), and anti-NR2b (rabbit polyclonal; Upstate Biotechnology). Data are expressed as a ratio of optical densities from sequential probes of the same immunoblot, circumventing the need to normalize to a gel-loading control. The relationship between optical density and protein concentration is linear along the range used in this study (Heynen et al., 2000). All immunoblots were performed with the experimenter blind to experimental conditions.

\section{Results}

Visual deprivation reactivates persistent, juvenile-like ocular dominance plasticity in adults

Pigmented Long-Evans rats were raised in a normal lighted environment (12 h light/dark cycle) until adulthood (>P60), then placed into a light-tight dark room for $10 \mathrm{~d}$ of visual deprivation. VEPs were used to measure the response of the binocular visual cortex to monocular deprivation. In rodents, $\sim 90 \%$ of retinal ganglion cell axons decussate at the optic chiasm, resulting in larger VEPs in response to contralateral $(C)$ versus ipsilateral $(I)$ eye stimulation (Porciatti et al., 1999; Sawtell et al., 2003; Pham et al., 2004). As expected, brief (3 d) monocular deprivation did not affect the VEP C/I in the visual cortex ipsilateral (Ipsi) or contralateral (Contra) to the occluded eye (average \pm SEM: Ipsi, $2.48 \pm 0.13 ;$ Contra, $2.38 \pm 0.18 ; n=5 ; p>0.05$, paired $t$ test) (Fig. $1 A$ ), confirming the absence of rapid ocular dominance plasticity in adults. However, when brief monocular deprivation was preceded by $10 \mathrm{~d}$ of visual deprivation, we observed a significant difference in the contralateral bias in the visual cortex contralateral versus ipsilateral to the occlusion (average \pm SEM: Contra, $0.82 \pm 0.04$; Ipsi, $3.13 \pm 0.17 ; n=5 ; p<0.01$, paired $t$ test) (Fig. $1 B$ ), demonstrating the reactivation of rapid ocular dominance plasticity in adults.

The rapid ocular dominance shift that we observe in visually deprived (VD) adults may be because of (1) a depression of the response to stimulation of the deprived eye, typically seen only in juveniles or (2) a potentiation of the response to stimulation of the nondeprived eye, which emerges slowly in juveniles and adults. To distinguish between these two possibilities, we com-
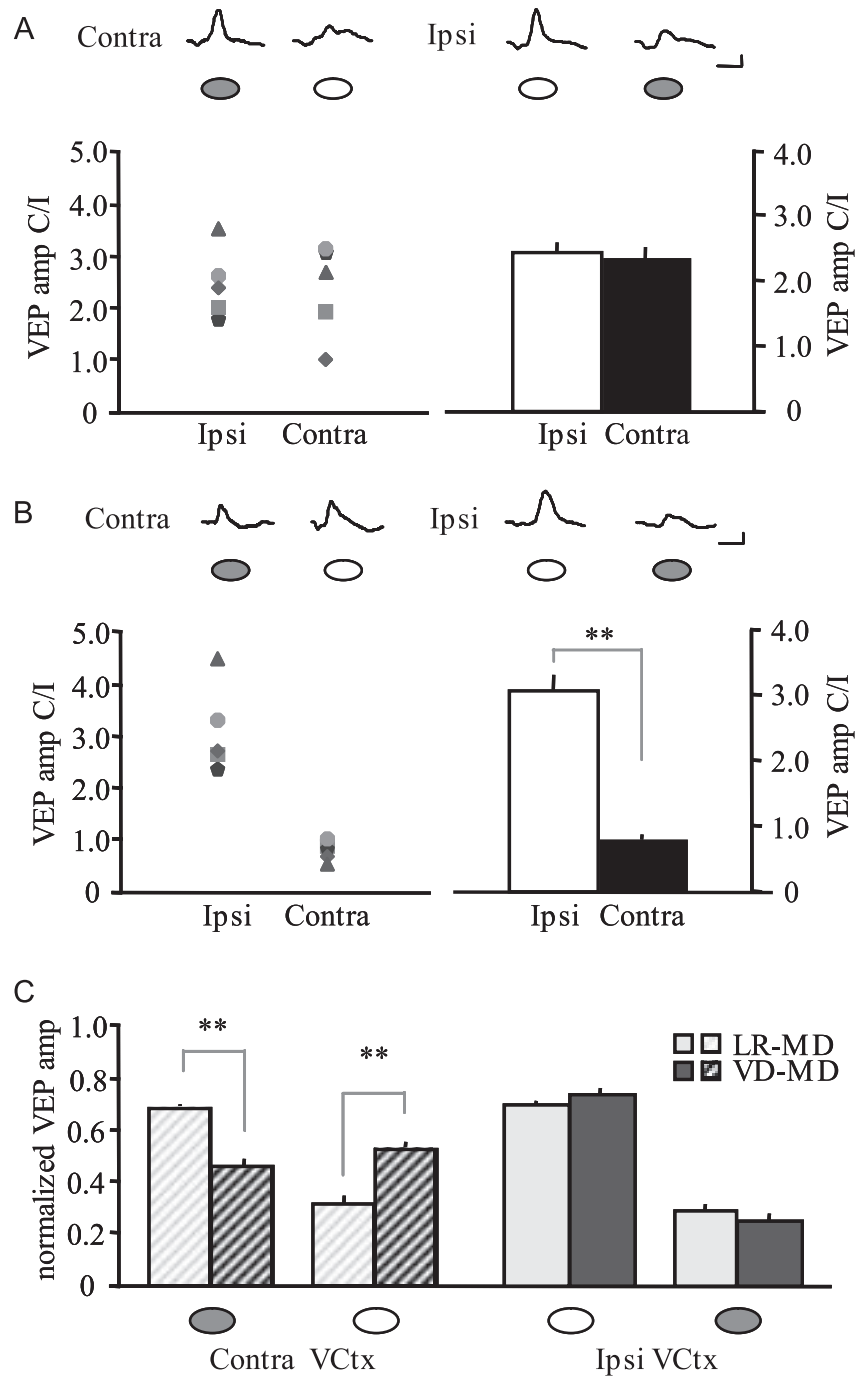

Figure 1. Visual deprivation reactivates rapid, juvenile-like ocular dominance plasticity in the adult visual cortex. $\boldsymbol{A}$, Brief ( $3 \mathrm{~d})$ MD does not induce an ocular dominance shift in lightreared adults. Left, VEP amplitudes $(C / I)$ recorded from each subject in the visual cortex ipsilateral and contralateral to the occluded eye. Right, Summary data reveal no significant difference in VEP C// across two hemispheres. Inset, Representative VEPs (average of 100 trials) recorded from each hemisphere in response to stimulation of the occluded (filled circle) and open (open circle) eye. Calibration: $100 \mathrm{~ms}, 50 \mu$ V. B, BriefMD after $10 \mathrm{~d}$ of visual deprivation induces a significant ocular dominance shift. Left, VEP C// from each subject. Right, Summary data reveals a significant difference in VEP (/I across two hemispheres, indicating an ocular dominance shift ( ${ }^{* *} p<0.01$, paired $t$ test). Inset, Representative VEPs (average of 100 trials). C, In visually deprived adults, brief MD induces a significant depression in the response to stimulation of the occluded eye and a significant potentiation in the response to stimulation of open eye in the visual cortex (VCtx) contralateral to the occlusion $\left({ }^{* *} p<0.01\right.$ vs light-reared controls, unpaired $t$ test). No difference in the response to stimulation of either eye was observed in the visual cortex ipsilateral to the occlusion ( $p>0.05$, unpaired $t$ test). amp, Amplitude. Error bars represent SEM.

pared VEP amplitudes in response to stimulation of each eye after brief monocular deprivation. To facilitate comparison across animals, VEP amplitudes (microvolts) at each recording site were normalized to the sum of the response to stimulation of the contralateral and ipsilateral eye $(C+I)$, which did not differ across hemispheres ( $p>0.05$, paired $t$ test). VEPs recorded in the visual cortex contralateral to the occlusion revealed two responses to brief monocular deprivation in visually deprived adults: a decrease in the response to stimulation of the occluded eye [average \pm SEM (norm to $C+I$ ): light-reared (LR), $0.67 \pm 0.02, n=$ $5 ; \mathrm{VD}, 0.46 \pm 0.02, n=5 ; p<0.01$, unpaired $t$ test] (Fig. $1 C$ ) and 




Rearing Conditions before MD

Figure 2. Visual deprivation induces persistent reactivation of rapid ocular dominance plasticity in adults. Adults received brief $M D$ immediately after $10 \mathrm{~d}$ of visual deprivation or when 1 , 3, or $7 \mathrm{~d}$ of binocular vision was allowed after visual deprivation. C// VEPs reveal that brief MD continued to effectively induce an OD shift in the visual cortex (VCtx) contralateral to the occluded eye, when 1 or $3 \mathrm{~d}$, but not $7 \mathrm{~d}$, of binocular vision follows visual deprivation ${ }^{* *} p<0.01$, one-way ANOVA with post hoc analysis). We see no difference in the (/IVEP in the visual cortex ipsilateral to the occluded eye. Error bars represent SEM.

an increase in the response to stimulation of the open eye [average \pm SEM (norm to $C+I$ ): $\mathrm{LR}, 0.33 \pm 0.02 ; \mathrm{VD}, 0.54 \pm 0.02$; $p<0.01$, unpaired $t$ test]. We observed no effect in the hemisphere ipsilateral to the occlusion in response to stimulation of the open eye [average \pm SEM (norm to $C+I$ ): LR, $0.71 \pm 0.01$; $\mathrm{VD}, 0.74 \pm 0.01 ; p>0.05$, unpaired $t$ test $]$ or occluded eye (LR, $0.29 \pm 0.01 ; \mathrm{VD}, 0.26 \pm 0.01 ; p>0.05$, unpaired $t$ test) (Fig. $1 C$ ).

We next tested the durability of the enhanced ocular dominance plasticity induced by visual deprivation by imposing a period of binocular vision (BV) between visual deprivation and monocular deprivation. Remarkably, brief monocular deprivation continued to effectively induce an ocular dominance shift even when 1-3 d of binocular vision followed visual deprivation. The response to brief monocular deprivation in subjects receiving $7 \mathrm{~d}$ of binocular vision was indistinguishable from controls (VEP C/I in visual cortex contralateral to the occlusion: $\mathrm{VD}, 0.82 \pm 0.04, n=$ 5; VD-BV1, $0.94 \pm 0.05, n=5$; VD-BV3, $1.19 \pm 0.09, n=5$; VDBV7, $2.86 \pm 0.57, n=4$; LR, $2.38 \pm 0.18, n=5$; one-way ANOVA, $F_{(4,16)}=8.858, p<0.01$ post hoc analysis) (Fig. 2). We observed no difference in the contralateral bias of the visual cortex ipsilateral to the occlusion across experimental conditions (VD, $3.13 \pm 0.17, n=$ 5; VD-BV1, $3.32 \pm 0.08, n=5$; VD-BV3, $3.13 \pm 0.47, n=5$; VDBV7, $2.76 \pm 0.38, n=4$; LR, $2.48 \pm 0.13, n=5$; one-way ANOVA, $\left.F_{(4,16)}=0.516, p>0.05\right)$. This suggests that visual deprivation promotes a persistent reactivation of juvenile-like ocular dominance plasticity in adult visual cortex.

\section{Visual deprivation reverses two molecular correlates of cortical maturation}

To begin to explore the mechanisms by which visual deprivation enhances ocular dominance plasticity, we examined levels of known molecular correlates of cortical maturation in visually deprived juveniles and adults. An antibody that recognizes the $\beta 2$ and the $\beta 3$ subunits of the $\mathrm{GABA}_{\mathrm{A}} \mathrm{R}$ was used to track changes in inhibition, because the majority of fast cortical inhibition is mediated by $\mathrm{GABA}_{\mathrm{A}}$ Rs containing these subunits (Li and De Blas, 1997). Similarly, we used an antibody that recognizes the GluR2 subunit of the AMPAR to track changes in excitation, because the majority of fast cortical excitation is mediated by AMPARs containing this subunit (Wenthold et al., 1992). Quantitative immu-
A

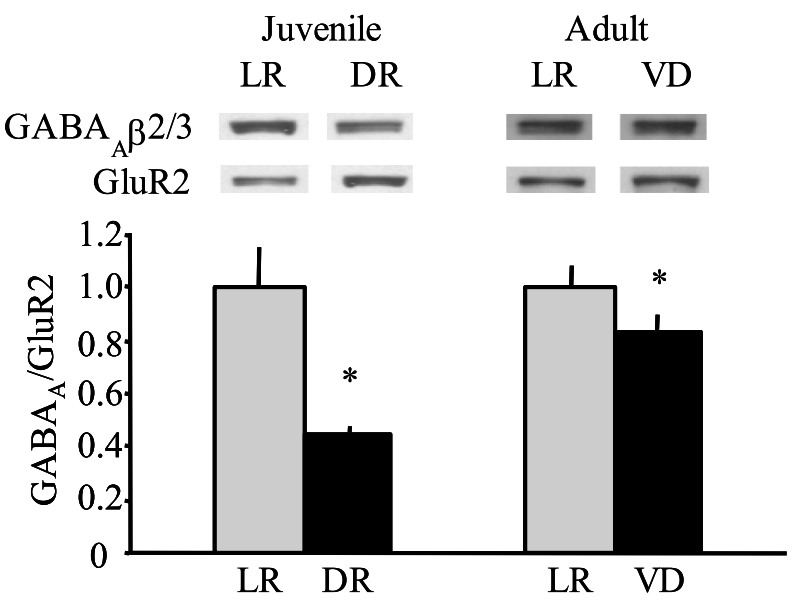

B

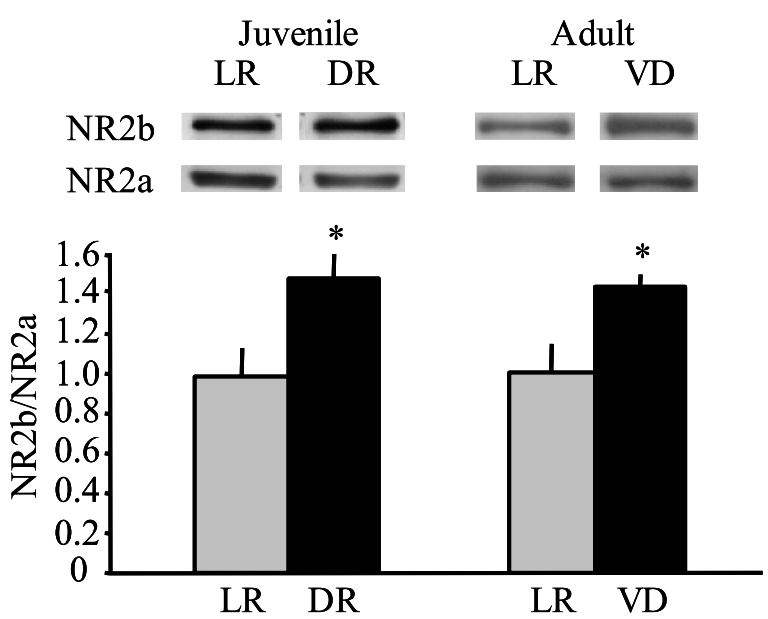

Figure 3. Visual deprivation in adults reverses two molecular correlates of cortical maturation. $\boldsymbol{A}$, Top, Representative immunoblots for $\mathrm{GABA}_{A} \beta 2 / 3$ and GluR2 from juvenile and adult visual cortical homogenate. Bottom, Summary data demonstrate that visual deprivation induces a significant decrease in $\mathrm{GABA}_{A} \beta 2 / 3$ relative to GluR2 in juveniles and adults ( ${ }^{*} p<0.05$, unpaired $t$ test). $\boldsymbol{B}$, Top, Representative immunoblots for NR2b and NR2a from juvenile and adult visual cortical synaptoneurosomes. Bottom, Summary data demonstrate that visual deprivation induces a significant increase in NR2b relative to NR2a in juveniles and adults ( ${ }^{*} p<0.01$, unpaired $t$ test). Data were normalized to age-matched LR for display. Error bars represent SEM.

noblotting revealed a significant decrease in $\mathrm{GABA}_{\mathrm{A}} \beta 2 / 3$ relative to GluR2 in visual cortex in juveniles (P28) dark reared (DR) from birth, compared with age-matched light-reared controls (average \pm SEM: LR, $1.15 \pm 0.08, n=7 ; \mathrm{DR}, 0.67 \pm 0.21, n=7$; $p<0.05$, unpaired $t$ test) (Fig. $3 A$ ). To examine the effect of visual deprivation on the adult visual cortex, quantitative immunoblotting was performed on the visual cortex of light-reared adults (P70) or age-matched littermates visually deprived for $10 \mathrm{~d}$ beginning at P60. We see a significant decrease in the level of $\mathrm{GABA}_{\mathrm{A}} \beta 2 / 3$ relative to GluR2 in visually deprived versus lightreared adults (average \pm SEM: LR, $1.36 \pm 0.13, n=8$; VD, $1.07 \pm$ $0.08, n=8 ; p<0.05$, unpaired $t$ test) (Fig. $3 A$ ). No difference in $\mathrm{GABA}_{\mathrm{A}} \beta 2 / 3$ relative to GluR2 was observed in the frontal cortex of these subjects (average \pm SEM: LR, $1.41 \pm 0.12, n=8$; VD, $1.48 \pm 0.14, n=8 ; p>0.05$, unpaired $t$ test).

Another well documented consequence of experiencedependent cortical maturation is the decrease in the level of NR2b- relative to NR2a-containing NMDARs in the visual cortex. Quantitative immunoblotting for NR2b and NR2a was performed on synaptoneurosomes prepared from the visual cortex of dark-reared juveniles (P28) or visually deprived adults (P70) 
and their light-reared age-matched controls. We see a significant increase in NR2b relative to NR2a in dark-reared versus lightreared juveniles (average \pm SEM: LR, $0.85 \pm 0.09, n=12$; DR, $1.20 \pm 0.13, n=13 ; p<0.02$, unpaired $t$ test) (Fig. $3 B$ ) as a result of a decrease in NR2a [average \pm SEM (norm to standard): LR, $0.64 \pm 0.06$; DR, $0.49 \pm 0.06 ; p<0.05$, unpaired $t$ test] rather than an increase in NR2b [average \pm SEM (norm to standard): $(\mathrm{LR}, 0.51 \pm 0.04 ; \mathrm{DR}, 0.56 \pm 0.06 ; p>0.05$, unpaired $t$ test $]$. In addition, we see a significant increase in NR2b relative to NR2a in visually deprived versus light-reared adults (average \pm SEM: LR, $0.82 \pm 0.11, n=6 ; \mathrm{VD}, 1.20 \pm 0.07, n=9 ; p<0.01$, unpaired $t$ test). Interestingly, the high level of NR2b relative to NR2a in visually deprived adults is attributable to an increase in NR2b [average \pm SEM (norm to standard): LR, $0.62 \pm 0.10$; VD, $1.04 \pm$ $0.12 ; p<0.02$, unpaired $t$ test] rather than a decrease in NR2a [average \pm SEM (norm to standard): LR, $0.75 \pm 0.06$; VD, $0.89 \pm$ $0.12 ; p>0.05$, unpaired $t$ test $]$. We see no significant difference in NR2b relative to NR2a in the frontal cortex of these subjects (average \pm SEM: LR, $0.86 \pm 0.12, n=6 ; \mathrm{VD}, 1.03 \pm 0.06, n=9$; $p>0.05$, unpaired $t$ test).

\section{Discussion}

The shift in ocular dominance induced by monocular deprivation is a sensitive index of the synaptic plasticity available in the binocular visual cortex. In juveniles, brief $(\leq 3 \mathrm{~d})$ monocular deprivation induces a rapid depression in the response to stimulation of the deprived eye, followed by a slowly emerging potentiation of the response to stimulation of the nondeprived eye (Frenkel and Bear, 2004). In adults, brief monocular deprivation is ineffective. However, a longer period of monocular deprivation ( $\geq 5 \mathrm{~d}$ ) can induce a shift in ocular dominance, attributable entirely to potentiation of the response to stimulation of the nondeprived eye (Sawtell et al., 2003). Here, we show that persistent, juvenile-like ocular dominance plasticity can be restored in the adult visual cortex by visual deprivation. In visually deprived adults, brief monocular deprivation induces a rapid depression in the response to stimulation of the deprived eye, previously only reported in juveniles, and an acceleration of the potentiation of the response to stimulation of the nondeprived eye, previously found to emerge slowly in juveniles and adults. This noninvasive manipulation provides additional evidence that the adult visual cortex maintains significant potential for synaptic plasticity and that ocular dominance plasticity can be enhanced by visual deprivation throughout life.

Our ability to demonstrate reactivation of rapid, juvenile-like ocular dominance plasticity in the adult visual cortex relied on the use of VEPs to assay the effects of monocular deprivation. Previous experiments have demonstrated that VEPs allow for reliable detection of ocular dominance (Porciatti et al., 1999; Sawtell et al., 2003) and that measurements of visual acuity obtained from VEPs agree with data obtained from behavioral assays in all species examined, including humans (Allen et al., 1986). Curiously, ocular dominance shifts in response to prolonged monocular deprivation have been revealed in the adult visual cortex of rats, cats, and primates by VEP analysis, immediate-early gene expression, and $\alpha$-calcium/calmodulindependent protein kinase II staining (Hendry and Kennedy, 1986; Sawtell et al., 2003; Pham et al., 2004; Tagawa et al., 2005) but have not been detected by single-unit recordings. Emerging evidence suggests that ocular dominance plasticity in adults, but not juveniles, can be acutely masked by sodium pentobarbital (Pham et al., 2004), an anesthetic typically used for single-unit recordings. We assay VEPs under urethane anesthesia (Guidel stage
III-3, characterized by $0.5-3 \mathrm{~Hz}$ spontaneous activity), which may allow the detection of synaptic changes that are masked by sodium pentobarbital. Developmental changes in the sensitivity of $\mathrm{GABA}_{\mathrm{A}} \mathrm{Rs}$ to the agonist properties of sodium pentobarbital may underlie these differences and explain the success of the VEP method for the study of adult ocular dominance plasticity.

Increasing evidence suggests that the balance between inhibition and excitation may determine the level of activity-dependent synaptic plasticity available to cortical circuits (Fagiolini and Hensch, 2000; Rozas et al., 2001). We showed recently that deafferentation-induced remapping of somatosensory cortex involves multiple adjustments of $I / E$ in the deafferented cortex of adult raccoons (He et al., 2004). The low level of $\mathrm{GABA}_{\mathrm{A}}$ Rs relative to AMPARs that we observe in the visual cortex of juveniles dark-reared from birth is consistent with small IPSCs and large EPSCs recorded from visual cortical pyramidal neurons in darkreared rodents (Desai et al., 2002; Morales et al., 2002). A low level of $\mathrm{GABA}_{\mathrm{A}}$ Rs relative to AMPARs was also observed in the adult visual cortex after visual deprivation, suggesting that even in adulthood, visual deprivation can drive the visual system to a more immature state. A low level of inhibition relative to excitation may be required to allow the visual cortex to respond rapidly to manipulations in visual input.

Activation of the NMDA subtype of glutamate receptor is required for many forms of activity-dependent synaptic plasticity, including deprivation-induced ocular dominance shifts (Bear et al., 1990; Sawtell et al., 2003). Here, we show that visual deprivation at any age results in NMDARs with an immature composition, characterized by a high level of the NR2b subunit relative to NR2a. However, in juveniles, visual deprivation appears to prevent the insertion of NR2a-containing NMDARs into the synapse (Quinlan et al., 1999), whereas in adults, visual deprivation appears to stimulate the delivery of NR2b-containing NMDARs to the synapse. In both cases, the deprivation-induced regulation of NMDAR subunit composition would significantly impact the characteristics of NMDARdependent synaptic plasticity. Interestingly, NR2a knock-out mice have a significantly reduced ocular dominance shift in response to 4-5 d monocular deprivation (Fagiolini et al., 2003).

It has been proposed previously that the ratio of synaptic NR2bto NR2a-containing NMDARs determines the threshold for NMDAR-dependent long-term potentiation (Gold and Bear, 1994; Quinlan et al., 1999; Tang et al., 1999). In the juvenile visual cortex, when NR2b-containing NMDARs prevail, the threshold for NMDAR-dependent LTP is low. Over the course of development, there is an experience-dependent decrease in NR2b-containing NMDARs and an associated increase in the threshold for LTP (Kirkwood et al., 1996). The correlation between high levels of NR2bcontaining NMDARs and a low threshold for LTP has also been demonstrated after learning (Quinlan et al., 2004), after transgenic overexpression of NR2b (Tang et al., 1999), and after cortical lesions (Huemmeke et al., 2004). The increase in the ratio of NR2b to NR2a observed in visually deprived adults is predicted to lower the threshold for activity-dependent synaptic potentiation, consistent with the rapid potentiation observed in response to stimulation of the nondeprived eye. However, we cannot rule out the possibility that the observed increase in NR2b occurs in a perisynaptic population (Li et al., 1998; Tovar and Westbrook, 2002; Yashiro et al., 2005), contributing to synaptic efficacy independently of synaptic NMDARs (Liu et al., 2004; Massey et al., 2004), or that the direction of the synaptic response is independent of NMDAR subunit composition (Berberich et al., 2005; Zhao et al., 2005).

Ocular dominance plasticity in adults has been shown previously to be facilitated by enzymatic degradation of extracellular 
matrix components (Pizzorusso et al., 2002), demonstrating that the potential for synaptic plasticity in the visual cortex persists throughout lifetime. Here, we show that $10 \mathrm{~d}$ of visual deprivation is sufficient to reactivate rapid, juvenile-like ocular dominance plasticity. Surprisingly, the enhanced ocular dominance plasticity that we observe after visual deprivation persists, even after $3 \mathrm{~d}$ of binocular vision. Such a noninvasive method to restore rapid ocular dominance plasticity holds potential therapeutic promise, because the ability to reverse the visual deficits in human amblyopia decreases with age (Mitchell and MacKinnon, 2002).

Note added in proof. Evidence that the potential for ocular dominance plasticity can be regulated by visual experience was recently provided by Hofer et al., (2006) using optical imaging of intrinsic signals in the mouse visual cortex to demonstrate that monocular deprivation in juveniles facilities ocular dominance plasticity in adults.

\section{References}

Allen D, Norcia AM, Tyler CW (1986) Comparative study of electrophysiological and psychophysical measurement of the contrast sensitivity function in humans. Am J Optom Physiol Opt 63:442-449.

Bear MF, Kleinschmidt A, Gu QA, Singer W (1990) Disruption of experience-dependent synaptic modifications in striate cortex by infusion of an NMDA receptor antagonist. J Neurosci 10:909-925.

Berberich S, Punnakkal P, Jensen V, Pawlak V, Seeburg PH, Hvalby O, Kohr G (2005) Lack of NMDA receptor subtype selectivity for hippocampal long-term potentiation. J Neurosci 25:6907-6910.

Carmignoto G, Vicini S (1992) Activity-dependent decrease in NMDA receptor responses during development of the visual cortex. Science 258:1007-1011.

Cynader M (1983) Prolonged sensitivity to monocular deprivation in darkreared cats: effects of age and visual exposure. Brain Res 284:155-164.

Desai NS, Cudmore RH, Nelson SB, Turrigiano GG (2002) Critical periods for experience-dependent synaptic scaling in visual cortex. Nat Neurosci 5:783-789.

Fagiolini M, Hensch TK (2000) Inhibitory threshold for critical period activation in primary visual cortex. Nature 404:183-186.

Fagiolini M, Pizzorusso T, Berardi N, Domenici L, Maffei L (1994) Functional postnatal development of the rat primary visual cortex and the role of visual experience: dark rearing and monocular deprivation. Vision Res 34:709-720.

Fagiolini M, Katagiri H, Miyamoto H, Mori H, Grant SG, Mishina M, Hensch TK (2003) Separable features of visual cortical plasticity revealed by $\mathrm{N}$-methyl-D-aspartate receptor 2A signaling. Proc Natl Acad Sci USA 100:2854-2859.

Frenkel MY, Bear MF (2004) How monocular deprivation shifts ocular dominance in visual cortex of young mice. Neuron 44:917-923.

Gold JI, Bear MF (1994) A model of dendritic spine $\mathrm{Ca}^{2+}$ concentration exploring possible bases for a sliding synaptic modification threshold. Proc Natl Acad Sci USA 91:3941-3945.

Gordon JA, Stryker MP (1996) Experience-dependent plasticity of binocular responses in the primary visual cortex of the mouse. J Neurosci 16:3274-3286.

He H-Y, Rasmusson DD, Quinlan EM (2004) Progressive elevations in AMPA and $\mathrm{GABA}_{\mathrm{A}}$ receptors in deafferented somatosensory cortex. J Neurochem 90:1186-1193.

Hendry SH, Kennedy MB (1986) Immunoreactivity for a calmodulindependent protein kinase is selectively increased in macaque striate cortex after monocular deprivation. Proc Natl Acad Sci USA 83:1536-1540.

Heynen AJ, Bear MF (2001) Long-term potentiation of thalamocortical transmission in the adult visual cortex in vivo. J Neurosci 21:9801-9813.

Heynen AJ, Quinlan EM, Bae DC, Bear MF (2000) Bidirectional, activitydependent regulation of glutamate receptors in the adult hippocampus in vivo. Neuron 28:527-536.

Heynen AJ, Yoon BJ, Liu CH, Chung HJ, Huganir RL, Bear MF (2003) Molecular mechanism for loss of visual cortical responsiveness following brief monocular deprivation. Nat Neurosci 6:854-862.

Hofer SB, Mrsic-Flogel TD, Bonhoeffer T, Hubener M (2006) Prior experience enhances plasticity in adult visual cortex. Nat Neurosci 9:127-32.
Huang ZJ, Kirkwood A, Pizzorusso T, Porciatti V, Morales B, Bear MF, Maffei L, Tonegawa S (1999) BDNF regulates the maturation of inhibition and the critical period of plasticity in mouse visual cortex. Cell 98:739-755.

Hubel DH, Wiesel TN (1970) The period of susceptibility to the physiological effects of unilateral eye closure in kittens. J Physiol (Lond) 206:419-436

Huemmeke M, Eysel UT, Mittmann T (2004) Lesion-induced enhancement of LTP in rat visual cortex is mediated by NMDA receptors containing the NR2B subunit. J Physiol (Lond) 559:875-882.

Kirkwood A, Rioult MC, Bear MF (1996) Experience-dependent modification of synaptic plasticity in visual cortex. Nature 381:526-528.

Li JH, Wang YH, Wolfe BB, Krueger KE, Corsi L, Stocca G, Vicini S (1998) Developmental changes in localization of NMDA receptor subunits in primary cultures of cortical neurons. Eur J Neurosci 10:1704-1715.

Li M, De Blas AL (1997) Coexistence of two beta subunit isoforms in the same gamma-aminobutyric acid type A receptor. J Biol Chem 272:16564-16569.

Liu L, Wong TP, Pozza MF, Lingenhoehl K, Wang Y, Sheng M, Auberson YP, Wang YT (2004) Role of NMDA receptor subtypes in governing the direction of hippocampal synaptic plasticity. Science 304:1021-1024.

Massey PV, Johnson BE, Moult PR, Auberson YP, Brown MW, Molnar E, Collingridge GL, Bashir ZI (2004) Differential roles of NR2A and NR2B-containing NMDA receptors in cortical long-term potentiation and long-term depression. J Neurosci 24:7821-7828.

Mitchell DE, MacKinnon S (2002) The present and potential impact of research on animal models for clinical treatment of stimulus deprivation amblyopia. Clin Exp Optom 85:5-18.

Morales B, Choi SY, Kirkwood A (2002) Dark rearing alters the development of GABAergic transmission in visual cortex. J Neurosci 22:8084-8090.

Pham TA, Graham SJ, Suzuki S, Barco A, Kandel ER, Gordon B, Lickey ME (2004) A semi-persistent adult ocular dominance plasticity in visual cortex is stabilized by activated CREB. Learn Mem 11:738-747.

Pizzorusso T, Medini P, Berardi N, Chierzi S, Fawcett JW, Maffei L (2002) Reactivation of ocular dominance plasticity in the adult visual cortex. Science 298:1248-1251.

Porciatti V, Pizzorusso T, Maffei L (1999) The visual physiology of the wild type mouse determined with pattern VEPs. Vision Res 39:3071-3081.

Quinlan EM, Philpot BD, Huganir RL, Bear MF (1999) Rapid, experiencedependent expression of synaptic NMDA receptors in visual cortex in vivo. Nat Neurosci 2:352-357.

Quinlan EM, Lebel D, Brosh I, Barkai E (2004) A molecular mechanism for stabilization of learning-induced synaptic modifications. Neuron 41:185-192.

Rozas C, Frank H, Heynen AJ, Morales B, Bear MF, Kirkwood A (2001) Developmental inhibitory gate controls the relay of activity to the superficial layers of the visual cortex. J Neurosci 21:6791-6801.

Sawtell NB, Frenkel MY, Philpot BD, Nakazawa K, Tonegawa S, Bear MF (2003) NMDA receptor-dependent ocular dominance plasticity in adult visual cortex. Neuron 38:977-985.

Tagawa Y, Kanold PO, Majdan M, Shatz CJ (2005) Multiple periods of functional ocular dominance plasticity in mouse visual cortex. Nat Neurosci 8:380-388.

Tang YP, Shimizu E, Dube GR, Rampon C, Kerchner GA, Zhuo M, Liu G, Tsien JZ (1999) Genetic enhancement of learning and memory in mice. Nature 401:63-69.

Tovar KR, Westbrook GL (2002) Mobile NMDA receptors at hippocampal synapses. Neuron 34:255-264.

Wenthold RJ, Yokotani N, Doi K, Wada K (1992) Immunochemical characterization of the non-NMDA glutamate receptor using subunit-specific antibodies. Evidence for a hetero-oligomeric structure in rat brain. J Biol Chem 267:501-507.

Yashiro K, Corlew R, Philpot BD (2005) Visual deprivation modifies both presynaptic glutamate release and the composition of perisynaptic/extrasynaptic NMDA receptors in adult visual cortex. J Neurosci 25:11684-11692.

Zhao MG, Toyoda H, Lee YS, Wu LJ, Ko SQ, Zhang XH, Jia Y, Shum F, Xu J, Li BM, Kaang BK, Zhuo M (2005) Roles of NR2b subtype receptor in prefrontal long-term potentiation and contextual fear memory. Neuron $47: 859-872$. 